\title{
Strates
}

STRATES Matériaux pour la recherche en sciences sociales

Hors-série | 2002

Parcours dans la recherche urbaine, Michel Rochefort, un géographe engagé

\section{Un des rares mandarins à n'avoir jamais été mandarin}

\section{Raymond Guglielmo}

\section{OpenEdition}

\section{Journals}

Édition électronique

URL : http://journals.openedition.org/strates/527

DOI : $10.4000 /$ strates. 527

ISSN : $1777-5442$

Éditeur

Laboratoire Ladyss

Édition imprimée

Date de publication : 1 janvier 2002

ISSN : 0768-8067

Référence électronique

Raymond Guglielmo, « Un des rares mandarins à n'avoir jamais été mandarin », Strates [En ligne], Hors-série | 2002, mis en ligne le 02 mai 2005, consulté le 08 septembre 2020. URL : http:// journals.openedition.org/strates/527 ; DOI : https://doi.org/10.4000/strates.527

Ce document a été généré automatiquement le 8 septembre 2020.

Tous droits réservés 


\title{
Un des rares mandarins à n'avoir jamais été mandarin
}

\author{
Raymond Guglielmo
}

1 Je commencerai ce papier par une double constatation : tout d'abord Michel est pour moi un très cher et très vieil ami. Cette amitié remonte à 1951, date à laquelle nous avons, l'un et l'autre, franchi l'abominable cap de l'agrégation. Près d'un demi-siècle : battu le record des «amis de trente ans ». Et surtout il s'agit d'une amitié d'une tout autre nature, sans arrière-pensée, sans réticence, toujours active et entretenue par une solide estime réciproque. J'ai tout de même un reproche amer à lui adresser : celui d'avoir fait, lors de cette session agrégative de 1951, une explication de carte meilleure que la mienne. Mais je lui ai pardonné depuis longtemps.

2 Ensuite Michel est à mes yeux un des rarissimes mandarins qui n'ait jamais été un mandarin. Pour moi, un peu anar sur les bords et qui ai pris pour devise : «Je refuse de commander parce que je refuse d'obéir », on mesure toute la valeur de cette estimation. Fin des années soixante/début des années soixante-dix, je fus un habitué du labo de Géographie humaine du 191 rue Saint Jacques et j'ai pu apprécier aussi bien son souci de ne pas se prendre au sérieux que celui de prendre au sérieux son travail et son comportement égalitaire vis-à-vis du personnel de ce labo. Enfin, j'ai très agréablement ressenti son engagement résolu dans le mouvement de mai 68 (dans le bon sens, bien sûr!) avec l'approbation unanime de ce personnel. Et ceci, quand tant d'autres de ses chers collègues choisissaient une tangente du genre « discrétion, disparition ", afin de ménager leur rôle lors du retournement de conjoncture qui n'allait pas tarder.

3 J'ai assisté à bon nombre de soutenances de thèses au cours desquelles je ne l'ai jamais vu traiter le candidat ou la candidate comme un menu fretin tiré du vivier des assistants, qui, une fois muni de la mention très honorable, devient brusquement, selon un rite bien établi, un membre, effectivement très honorable, de la secte. J'ai même vu et entendu Michel refuser, avec un plaisir pseudo-sadique, devant tout le jury réuni, sa soutenance de $3^{e}$ cycle à une candidate et lui annoncer illico que son mémoire était d'une qualité telle qu'on l'attendait quelques mois plus tard, à peine complété, pour en faire l'objet d'une soutenance de doctorat d'État! 
4 Michel, c'est aussi le prof dont on entend la voix de stentor, même assez loin des portes, pourtant fermées, du grand amphi. C'est également l'interlocuteur, sérieux certes, mais souvent plein d'humour, au regard parfois morne, mais brusquement pétillant, par exemple lorsqu'une dame, pas trop âgée et plutôt agréable à regarder, passe à portée de sa vue.

5 Mais si Michel est avant tout pour moi un ami très cher, je n'oublie pas, qu'on se rassure, qu'il est aussi un géographe qui, à l'image de Pierre George, notre maître à tous deux, a apporté quelque chose de neuf à la géographie. Le cas n'est pas si fréquent qu'on ne puisse le souligner avec force. En effet, alors que les pouvoirs publics s'épuisaient en vain à la recherche d'une limite d'une région qui fût vraiment géographique, pour chapeauter les départements et dépasser des régions de programme sans queue, ni tête, il a joué un rôle majeur dans cette remarquable trouvaille que constitue la métropole régionale, gouvernant un réseau urbain et définie non plus par tel ou tel flux dont les aires ne coïncidaient pas, mais par l'ampleur de son tertiaire supérieur.

6 Là, ce n'est certes pas de sa faute si cette louable entreprise d'aménagement régional sombra dans un piteux échec, parce que, entre autres, l'heure n'était plus aux grandes usines dans les grandes agglomérations (sources des grèves sauvages de 1968-74), mais aux usines modestes dans des villes petites et moyennes. Aussi bien, la crise économique étant survenue et le patronat ayant grâce à elle repris l'initiative dans les luttes sociales, un nouveau président de la République préconisait-il alors une amélioration des conditions et du cadre de vie (ah! l'écologie), plus facile dans les petites villes, plutôt que celle du niveau de vie, souvenir des "trente glorieuses", destructrices de l'environnement et auxquelles les grandes villes s'étaient si bien prêtées.

7 Mais ce n'est pas tout. Michel peut revendiquer à son actif l'énorme travail de recherche, urbaine surtout, mais pas seulement, qu'il a effectué dans et pour le TiersMonde, entre autres, au Brésil, pays auquel il m'a initié pendant les années soixantedix, un peu parce que j'avais opté pour Paris 8 (Vincennes) et plus encore à cause de l'orientation hexagonale de mes activités de chercheur. Mais nous nous sommes retrouvés plus tard, au Brésil précisément :São Paulo, Londrina, où il m’a fait visiter l'exploitation d'un Brésilien japonais; et puis, tout récemment, à Tunis, où Michel a participé à la mise en place d'un DEA à l'École nationale d'Architecture et d'Urbanisme et où, dans ce cadre, nous dispensions tous deux un enseignement de géographie urbaine.

8 Mais je crains d'avoir été déjà trop long, emporté par le plaisir de cette évocation et par le plaisir de lui faire plaisir. Alors je m'arrête. Dommage, car des souvenirs communs, j'en avais encore tout un lot. 